\title{
Quick Freeze
}

National Cancer Institute

\section{Source}

National Cancer Institute. Quick Freeze. NCI Thesaurus. Code C63521.

To freeze rapidly so as to preserve structure and prevent ice crystal formation. 